\title{
Competitive Intelligence through the Eyes of the Professionals
}

\author{
Jonathan Calof \\ Professor, Telfer School of Management a, calof@telfer.uottawa.ca \\ Leading research fellow, Laboratory for Economics of Innovation, Centre for Science and Technology, Innovation and \\ Information Policy, Institute for Statistical Studies and Economics of Knowledge (ISSEK)b , jcalof@hse.ru \\ Extraordinary Professor, Faculty of Economics and Management Sciences c, jonathan.calof@nwu.ac.za \\ a Telfer School of Management, University of Ottawa, 55 Laurier Avenue East, Ottawa, Ontario, Canada \\ ${ }^{\mathrm{b}}$ National Research University Higher School of Economics, 20 Myasnitskaya Str., Moscow, 101000, Russian Federation \\ ${ }^{\mathrm{c}}$ North-West University Potchefstroom, South Africa
}

Citation: Calof J. (2020) Competitive Intelligence through the Eyes of the Professionals. Foresight and STI Governance, vol. 14, no 3, pp. 6-13. DOI: 10.17323/2500-2597.2020.3.6.13

$\mathrm{T}$ his special issue of "Foresight and STI Governance" is devoted to different dimensions of Competitive Intelligence - one of the key fields of futures studies - and its relation to foresight methodology. Earlier we noted that CR and Foresight are complementary activities [Calof et al., 2015; Calof, 2017]. Further, in the interviews for this article held with CI association executives, both mentioned foresight as being a key part of their fields. Cam Mackey, the executive director of Strategic and Competitive Intelligence Professionals described intelligence as a domain that "bridges hindsight and foresight with insight. Cam credits Professor Craig Fleisher, a former SCIP President ${ }^{1}$ and prominent competitive intelligence author, with this phrase and Fleisher further says it takes an ecosystem view of the organizations' markets, customers, competitors, megatrends, and so forth.

Jim Miller, current board of directors member of the Special Libraries Association (SLA) and past member of the SLA competitive intelligence division executive board in explaining where the focus of CI was for SLA members when the competitive intelligence division was formed (in 2007) and where it is going stated "in 2007 the focus for our members was more on the collection side. Then our members moved towards the analysis piece and the future is foresight. Foresight is starting to show itself." The growing importance of foresight within both competitive intelligence associations indicates that to some extent there is overlap or complementarity within both fields.

\section{Competitive Intelligence and its Relationship with Foresight}

Each paper in this special issue provides the reader with the author's view of competitive intelligence. However, to give the reader a general definition for the introduction of this special issue, I provide the following. Du Toit [Du Toit, 2015] in a review of 338 peer-reviewed papers on CI gathered from ABI-Inform provided the following definition of competitive intelligence

"A process or practice that produces and disseminates actionable intelligence by planning, ethically and legally collecting, processing and analysing information from and about the internal and external or competitive environment in order to help decision-makers in decisionmaking and to provide a competitive advantage to the enterprise." [Du Toit, 2015, p. 15].

$\mathrm{Du}$ Toit further defined competitive intelligence in terms of its objective: 'Competitive intelligence (CI) is a strategic tool to facilitate the identification of potential opportunities and threats.' [Du Toit, 2013]. RodriguezSalvador et al. wrote that the objective of competitive intelligence was to support innovation [Rodriguez-Salvador et al., 2013].

The European Union's European Foresight Platform defines foresight as "a systematic, participatory, future-intelligence-gathering and medium-to-long-term vision-building process aimed at enabling present-day decisions and mobilizing joint actions." 2 Through this definition, foresight and CI are looked at in a sense, as a combined discipline, with foresight involving "futureintelligence-gathering." An integrated programme involving foresight, competitive intelligence and business analytics should not only decrease levels of uncertainty and risk but also lead to greater probabilities of policy uptake by its intended audience and also the early identification of industry opportunities [Calof et al., 2015].

Similarly, the National Research University, Higher School of Economics Institute for Statistical Studies and Economics of Knowledge text mining and seman-

\footnotetext{
Available at: https://www.scip.org/news/news.asp?id=439063, accessed 30.05.2020.

${ }^{2}$ Available at: http://www.foresight-platform.eu/community/forlearn/what-is-foresight/, accessed 13.06.2020.
} 
tic analysis system which is used for innovation policy research is called iFORA which stands for Intelligent Foresight Analytics (system). ${ }^{3}$ This view of competitive intelligence as a complementary and similar to foresight was also described in a Foresight journal special issue on North American foresight. ${ }^{4}$

Other research has pointed to competitive intelligence and foresight as not just being complementary and partners but as having significant overlap. There are many similarities between foresight and CI. For example, many of the analytical techniques used in foresight are also used in CI. Also, similar to foresight, CI gets much of the information used from experts outside the organization, secondary sources outside the organization, and combines this with internal information. The gathered information which is then analyzed is then used to support key decisions such as corporate or business strategy decisions, market entry decisions, product development and $\mathrm{R} \& \mathrm{D}$ [Calof, 2017, p. 34]. The complementarity of foresight and competitive intelligence has not only been recognized in the academic literature, it has also resulted in the formation of an academic special interest group, the Global Insight Network. ${ }^{5}$ Further, the 2020 Competitive and Market Intelligence Conference's academic track was focused on both competitive intelligence and foresight and also brought together foresight and competitive intelligence practitioners.

With academic research linking foresight and competitive intelligence as well as practitioners and CI associations also linking these two fields, this special issue has been designed to provide the Foresight and STI Governance community with articles that highlight competitive intelligence scholarship, practice, and teaching. In keeping with the aims of the journal, the selection of topics and papers in this special issue directly contributes to the interaction between researchers, policy makers, and other actors involved in the innovation processes by having articles written by CI researchers (from the academic community), CI practitioners (from both industry and government), and others involved in the competitive intelligence ecosystem.

The articles for this special issue have been written by many of the most respected members of the competitive intelligence community. The special issue starts with an article that looks at competitive intelligence (CI) from the perspective of a competitive intelligence associations. This article focuses on SCIP (Strategic and Competitive Intelligence Professionals), the largest global professional association for $\mathrm{CI}$ and the $\mathrm{CI}$ division of the Special Libraries Association (SLA).

\section{The Professional Associations View on State-of-Art CI and the Future of CI}

Associations have been the subject of extensive academic research that pointed to their important role in the development of relevant industries' ecosystems [Peters et al., 2019]. A 2018 special issue in the Journal of Management Enquiry focused on the roles and responsibilities of trade associations [Lawton, Rajwani, 2018]. Norqvist et. al [Norqvist et al, 2010] looked at the role of associations in terms of "coordinating, developing, and preserving their industries" while Greenwood et al. [Greenwood et al., 2002] looked at how a professional services association helped transform its industry. Rajwani et al. wrote "associations work to influence regulation, government policy, and public opinion on behalf of the collective needs and objectives of their members. They also serve as agents for disseminating and exchanging information within industries, and often act as informal regulators by setting voluntary standards of behavior for industry members." [Rajwani et al., 2015, p. 224]. The importance and role of associations as found in the literature suggests that the association should have a good overview of the field.

Two associations were selected for this special issue The Strategic and Competitive Intelligence Professionals (SCIP) and the Competitive Intelligence division of the Special Libraries Association (SLA). SCIP is considered the world's largest community of strategic, market and competitive intelligence professionals. The CI division of SLA is the third largest and most rapidly growing division of the Special Library Association. Increasingly, library and information science professionals are embracing CI and enhancing their contributions to their organizations. ${ }^{6}$ SLA defines itself as "a non-profit global organization for innovative information professionals and their strategic partners in business, government, academic, and other 'specialized' settings. ${ }^{7}$ Members of SCIP and SLA have all possibilities for best practice sharing, professional development, online training and education, networking, and access to world-class resources." The next section provides information from the associations' websites and from interviews with association leadership. For the SCIP, the interview was held with the Society's executive director (Cam Mackey) and for SLA, the interview was held with Jim Miller, an SLA board member who was part of the CI Division executive board.

\section{Strategic and Competitive Intelligence Professionals (SCIP)}

Founded in 1986, SCIP is the largest global association for competitive professionals 8 , with an established $\mathrm{CI}$ ecosystem and activities that besides competitive intelligence itself, include sales and marketing, market insights and research, business development, product management, innovation, strategy, and analysis. It consolidates competitive and market intelligence professionals, strategy leaders, solutions providers, professors, students, and non-profit experts, with a variety of employment histories.

Over $50 \%$ of SCIP members have 7+ years' experience as Intelligence Strategists, $30 \%$ are relatively new to the

\footnotetext{
${ }_{3}^{3}$ For more details see.: https://issek.hse.ru/data/2020/05/28/1550143786/iFORA_brochure.pdf, accessed 13.06.2020.

${ }^{4}$ Available at: https://www.emeraldgrouppublishing.com/journal/fs/north-american-foresight, accessed 13.06.2020.

${ }^{5}$ Available at: sprott.carleton.ca/insight, accessed 13.06.2020.

${ }^{6}$ Available at: https://www.sla.org/about-sla/, accessed 30.05.2020.

Available at: https://connect.sla.org/ci/home, accessed 30.05.2020.

${ }^{8}$ Available at: https://www.scip.org/page/About-Us, accessed 30.05.2020.
} 
discipline. By title, $26 \%$ are in market insight, $24 \%$ competitive intelligence, $21 \%$ strategy and analysis, and $8 \%$ listed as executives or other Profit and Loss titles.

SCIP serves wide range of industries: Pharmaceutical and Life Sciences, Professional Services, Insurance and Financial, Education, Aero and Defense, Manufacturing, Hi-tech, and Software. The focus is on helping the client organizations grow and the society has termed this "competitive intelligence for growth" (see Table 1).

In the interview, SCIP executive director Cam Mackey stated that CI bridges hindsight and foresight with in sight thus preventing "the loudest voice in the room" from driving the decisions. "If we do our job right we can create huge revenue opportunities and actually really reduce strategic risk." To do so requires attention to what Cam refers to as the data supply chain, a core component of creating actionable intelligence. "An equipment manufacturer, for example, has a vast, global supply chain that supplies it with hundreds of components. It spends a great deal of resources to ensure the quality, reliability, and ethical activities of that supply chain. CI needs to do the same, but with the Data Supply Chain.... Data quality and hygiene are often talked about, but as a community we need to do more to ensure that the data we use were collected in an ethical manner. And also that data and our analyses are shared in a transparent and responsible way.

Cam Mackey gives special focus to the SCIP Code of Ethics (see Box 1): “The Code of Ethics provides a true north, but it's (intentionally) not a substitute for internal company's policies. Just as importantly, it's not a substitute for professional and personal integrity. Whether organizations choose to have a centralized function or fragment responsibilities across other functions, effective Growth Intelligence is a strategic advantage. Without it, companies fly blind when making critical growth, strategic, and investment decisions".

In the early days, CI was focused more on understanding and predicting competitor behavior with an emphasis upon collection activities. In 2016, Nan Bulger, SCIP's executive director (Cam Mackey's predecessor) described where CI had been and how it was evolving.
"About 30 years ago, competitive intelligence focused primarily on the competitor, as a means of placing that competitor focus at the center of your decisions and understanding the competitive landscape, understanding what competitors were doing to compete, collecting data about competitors in the form of human-source collection, as well as secondary or printed-source collection... now it's really evolved into sophisticated decision support and analytics. It involves looking at competition, market environment, market sizing, and so forth for the purpose of really helping people understand how best to compete in a market" [Calof, 2016]. Nan Bulger called this new approach integrated intelligence.

In looking at both the skill set for the future and the impact upon the profession of artificial intelligence, Cam Mackey sees a further evolution in CI in the context of integrating across functions and the skill set of tomorrow's CI professional being more in analysis, developing insight, and becoming a more effective communicator of these insights to decision-makers. "It's an obvious point, but to be successful in the modern organization, you have to be cross-functional. It's less about our ability to collect and hoard data than ability to quickly pull out the insight and get it to the right person at the right time. Our power isn't in our controlling access to information. It's using that information with integrity to help our organizations reach their goals...Artificial Intelligence and the whole suite of data analytics tools have and will continue to transform our profession. However, it would be a mistake to assume that we'll be rendered obsolete by machines. Rather, the human element has never been more important for CI. As key elements of our process become streamlined or automated thanks to technology, there's an enormous opportunity, and obligation, to innovate in how we translate data (and analyses) into something that your organization will value. Much of that comes down to effective communication, at all stages of the process."

As to membership benefits, Cam McKee states: "People belong to an association to feel a sense of fellowship, to be part of a community of practice. But sometimes, they just want what I call "air support." They want best prac-

Table 1. SCIP's Principles of Intelligence for Growth

\begin{tabular}{|l|l|}
\hline \multicolumn{1}{|c|}{ Approach } & \multicolumn{1}{c|}{ Description } \\
\hline 360-Degree View & $\begin{array}{l}\text { Growth Intelligence takes an ecosystem view of an organization: markets, customers, competitors, } \\
\text { megatrends, etc. It also bridges hindsight and foresight with insight }\end{array}$ \\
\hline Filter Out the Noise & $\begin{array}{l}\text { We are awash in information. Intelligence Strategists reduce the sea of data to critical insights that } \\
\text { inform decisions to drive growth and de-risk strategies }\end{array}$ \\
\hline Evidence-Based & $\begin{array}{l}\text { Intelligence Strategists use a variety of tools and techniques to expose frailties in strategies and value } \\
\text { propositions (even if that leads to uncomfortable conversations with management) }\end{array}$ \\
\hline Element of Surprise & $\begin{array}{l}\text { Growth Intelligence can help an organization disrupt markets and win market share. Without it, } \\
\text { organizations may miss warning signs and be blindsided }\end{array}$ \\
\hline $\begin{array}{l}\text { Organizationally } \\
\text { Aligned }\end{array}$ & $\begin{array}{l}\text { Intelligence Strategists support numerous stakeholders (e.g. sales, strategy, marketing, product } \\
\text { management, etc.) in the growth value chain }\end{array}$ \\
\hline Just in Time & $\begin{array}{l}\text { By leveraging outstanding communication skills and technology, Intelligence Strategists deliver the } \\
\text { right insight to the right person at the right time }\end{array}$ \\
\hline Unimpeachable Ethics & $\begin{array}{l}\text { Growth Intelligence is grounded in the ethical collection and use of information (see our Code of } \\
\text { Ethics for more) }\end{array}$ \\
\hline \multicolumn{2}{|l}{ Source: SCIP website. Available at: https://www.scip.org/page/CI-MI-Basics-Topic-Hub, accessed 15.06.2020. } \\
\hline
\end{tabular}


Our Code of Ethics is the industry standard set of guidelines for ethical behavior for competitive and market intelligence activities. We expect our members, partners, staff, and the entire community to adhere to the Code, without exception. The Code is not a corporate policy; it contains guidelines by which companies and practitioners can set their own standards along the ethical spectrum.

- Elevate the Profession: To continually strive to increase the recognition and respect of the profession

- Always in Compliance: To comply with all applicable laws, domestic and international

- Transparent: To accurately disclose all relevant information, including one's identity and organization, prior to all interviews
- Conflict-Free: To avoid conflicts of interest in fulfilling one's duties

- Honest: To provide honest and realistic recommendations and conclusions in the execution of one's duties

- Act as an Ambassador: To promote this Code of Ethics within one's company, with third-party contractors and within the entire profession

- Strategically Aligned: To faithfully adhere to and abide by one's company policies, objectives and guidelines

We reserve the right to revoke and terminate any membership at any time if we determine that a member's activities are in direct violation of the Code of Ethics.

Source: SCIP website. Available at: https://www.scip.org/page/Ethical-Intelligence, accessed 15.06.2020.

tices and help doing their job better. They want someone to help elevate the brand of the function or the discipline of their profession. That's certainly the case with our community."

In defining how SCIP in particular provides benefits to its members, the website highlights several activities including ${ }^{9},{ }^{10}$ :

- being part of a community,

- attending the world's largest non-profit conference for intelligence strategists (SCIP IntelliCon),

- access to extensive online resource archives (1,000+ articles, research papers, case studies),

- access to CI training (virtual workshops, webinars, on-demand training, in-person workshops),

- networking with peers (including access to an online members directory, chapters, online community, virtual roundtables),

- access to talent and jobs (career center),

- high ethical standards (through the SCIP code of ethics, the violation of which can result in the expulsion of a member),

- access to service providers (including technology service providers as well as research and strategy needs),

- variety of free guidebooks on how to start CI Function, CI Ethics, Event Intelligence, and Market Intelligence/CI

\section{Special Libraries Association (SLA)}

The SLA (the Special Libraries Association) was established in1990 by a group of librarians who noted an increase in librarians working in more specialized settings (for example in corporations, government agencies, scientific organizations). In 2007 with growth in the number of SLA members (including librarians and other information professionals) involved in competitive intelligence, the CI division was formed. ${ }^{11}$

According to Jim Miller, this has arisen due to changes to libraries in general and more specifically transformations in the role of information professionals: "More and more organizations are reducing their corporate information centers and pushing the people from these centers into other parts of the organization and the SLA CI skill set has more defined value than someone who is just finding information.... The phasing out of traditional libraries and corporate information centres has led to a growth in the number of people transitioning to CI roles to provide more value-add for business."

The SLA CI Division defines Competitive intelligence (CI) as "a vital managerial process and activity that examines the external environment to support strategic AND tactical decision-making. Typically, it is not limited to researching competitor companies. Organizations examine their markets, customers, suppliers and so forth. All those aspects contribute to understanding one's competitive environment. Since comparison is involved, often there is great overlap with Knowledge Management to "know thyself" as well...

SLA members established the Competitive Intelligence Division in January 2007 to create a professional community that encompasses all aspects of this dynamic and essential organizational function. This includes planning, identifying intelligence needs, collecting and analyzing information, and providing strategic and tactical decision-support to management... We are comprised of information and intelligence professionals from a broad range of industries, organizations, and roles." ${ }^{12}$

The description provided by the CI SLA division fits well with the definition of CI provided earlier in this article that incorporates a CI process which includes planning,

\footnotetext{
9 Available at: https://www.scip.org/page/Membership-Value, accessed 30.05.2020.

${ }^{10}$ Available at: https://www.scip.org/page/Membership-Top-10-Tips, accessed 30.05.2020.

${ }^{11}$ Available at: https://connect.sla.org/ci/home, accessed 30.05.2020.

${ }^{12}$ Available at: https://connect.sla.org/ci/home, accessed 30.05.2020.
} 
Table 2. SLA CI Division Functions, Responsibilities, and Examples

\begin{tabular}{|c|c|}
\hline $\begin{array}{l}\text { Examples of } \\
\text { the members }\end{array}$ & $\begin{array}{l}\text { - Information professionals interested in enhancing their reference research background and/or analytical skills } \\
\text { - Knowledge/Record Managers building on internal benchmarking/content management backgrounds } \\
\text { - delivery of /Government Librarians whose work contributes to their organizations through timely, authoritative, } \\
\text { - MBA/Analysts and Journalists seeking to enhance their investigative abilities } \\
\text { - Academics supporting professorial research and/or institutional fundraising } \\
\text { - Independent Consultants offering secondary searches, etc. } \\
\text { - Primary Market Researchers } \\
\text { Patent Due Diligence Specialists }\end{array}$ \\
\hline $\begin{array}{l}\text { Member } \\
\text { functions/ } \\
\text { responsibilities }\end{array}$ & $\begin{array}{l}\text { - Administrative / Management / Supervisory } \\
\text { - Business Development / Prospecting } \\
\text { - CEO, President, Founder or other leadership roles } \\
\text { - Compction Development / Resource Selection } \\
\text { - Consulting } \\
\text { - Data / Statistics } \\
\text { - Information Architecture } \\
\text { : } \text { Journalist / Writer } \\
\text { - Pnowledge Management / Intellectual Property } \\
\text { - Recoct / Program Management } \\
\text { - Reference \& Research / Archivist } \\
\text { - Retired } \\
\text { - Sales / Account Management } \\
\text { - Taxont } \\
\text { - Teachomy / Metadata / Cataloging } \\
\text { - Trechnical Servining } \\
\text { - Transitioning / Job Seekers } \\
\text { Tebmasters / Emerging Technologies / IT / Systems }\end{array}$ \\
\hline
\end{tabular}

collecting information, analysis, and communications focused on the external environment for helping with tactical and strategic decisions. However, within this definition of competitive intelligence Jim Miller talked about their members being focused more on the collection and collection planning functions: "SLA is an organization where the majority of the members are librarians, library science, so how we better collect information and provide valuable intelligence that starts at the beginning of the process - research patent searching, process of looking of what has gone on before, lit review and a lot of secondary sources. We see members involved in patent searching for new product development, members in research units for technical intelligence and other areas. A lot of the SLA CI division members have been trained to ask the right questions to fully understand what are people asking for. They have a librarian skill set, search set, the ability to develop sophisticated search strings to get all sorts of information. Some of our members do this from an MBA background, others from a Library Science background.

The core skill set for these members based on a review of the SLA divisions programs and the interview with Jim Miller appears to be information searching, research planning, and source reliability assessment. The emphasis upon the collection side (including collection planning) of those that are part of SLA's CI division was also evident when Mr. Miller contrasted division members with SCIP members: "Most of our members are also SCIP members. However, finding the right information to put into the process is where our members are focused. For SCIP, CI is more focused on information from primary sources. For SLA, it is more focused on secondary information sources but there are people in SLA pushing into primary sources and interviewing".
Mr. Miller's description of the skill set and the focus of what SLA CI division members focus on fits with Cam Mackey's description of the data and information value chain mentioned earlier. As such, it positions this division as a key component of the CI ecosystem in terms of the early part of the value chain. This was further reinforced in the interview with Jim Miller: "We are pushing from our side telling the members to get involved earlier, to get involved early in your senior managers' processes". Thus, in contrasting membership of the SCIP and the SLA CI division, it would appear that SCIP represents the breadth of the data and information value chain while the SLA CI division is more focused on the early stage of this value chain.

The SLA CI division website provides a representative (not comprehensive) list of member function/responsibilities and examples of what their members do. This is provided in Table 2.

Similar to the discussion with Cam Mackey at SCIP, Jim Miller pointed to changes in his members' environment including artificial intelligence that is pushing their members to provide higher value added within their organizations. "In 2007 our members were focused more on the collection side. Our members are now moving towards the analysis piece and the future is foresight. If you talk to the practitioners, they are integrating strategic foresight methodologies to their work." The transition from a traditional role in collection to analysis and foresight has according to Mr. Miller arisen due to changes with their members' organizations and/or with their clients. "Corporations want to turn to people who will do interpretation, who understand the business and the goals. Not just collection but also interpretation... The trends analysis piece is also becoming bigger for our 
members' organizations they are getting involved in forward planning activities".

Artificial intelligence is another area that is providing opportunity for SLA CI division members and is fueling division growth. . Jim Miller stipulates that this is arising due to the SLA CI division members' skill sets, which are well suited for the challenges of AI and analytics. "For AI and sentiment analysis to be used effectively you need professionals who understand the context of the information, who understand keyword concepts, and collection planning. This is part of the SLA CI division member toolset".

Miller also points to other factors that suggest continued growth in the SLA CI division:

1) There will continue to be graduates in information and library science programs but there will be fewer jobs in traditional public libraries. In looking at where the CI division will be in ten years' time "it will be a bigger division focused more on how people with Library Science degrees can use their skill set other than just in a public library."

2)The rapid growth of the SLA CI division and a diversified membership base is partially a function of the growth of CI and CI-related areas but also significant changes in libraries and the role of information professionals. "More and more organizations are reducing their corporate information centers and pushing the people from these centers into other parts of the organization and the SLA CI skill set has more defined value than someone who is just finding information... The phasing out of traditional libraries and corporate information centres has lead to a growth in the number of people transitioning to CI roles to provide more value-add for business."

3) "The fact that CI cuts across numerous sectors allows for a wider pool of potential members. As well, the emerging growth of the application of CI in certain sectors such as regional economic development has allowed for and will continue to fuel increased growth in membership and collaboration with other communities for example pharmaceutical, military, and legal."

While the above explains both the rapid growth of the SLA CI division and its projections for continued growth, Mr. Miller does acknowledge that for its members "the primary focus is still on where is the best source for information and how to get it."

Similar to both the association literature and the discussions with SCIP, SLA CI division provides numerous benefits and programs to its members. Jim Miller says, in summary, the following: "The SLA CI Division provides its members with: networking opportunities; access to professional development webinars; access to CI presentations at annual conference; access to resource locators to find information that is useful for CI data collection (primarily secondary); mentoring opportunities for those taking intelligence/librarian education in post-secondary institutions... It helps to demonstrate that there are other career/employment opportunities for individuals with librarian/information management skills that go beyond the traditional librarian role of simply searching for information."
The SLA CI divisions website provides additional details in terms of the benefits of being part of the society.

"Membership also provides many opportunities for professional growth and development, and we are glad to collaborate along the way. That includes continuing educational programs - virtual and site-based, professional support for intelligence efforts, as well as many more resources."

\section{Conclusion}

This article sets the context for the competitive intelligence special issue. Interviews with leadership from two competitive intelligence associations (SCIP and SLA CI division) provide readers with an overview of how they define competitive intelligence and its role in organizations as well as how they see CI changing in the future. Within both organizations the emphasis in the evolution of their members' activities has been to move beyond collection activities only focused on the competition into more value-added activities including analysis and looking at broader environmental elements (customers, government, technology, economy, etc.). Both see artificial intelligence as being transformative and beneficial to their members. The overlap between competitive intelligence and foresight was also highlighted by both associations who indicated that their members are getting more involved in foresight activities.

With future-oriented, information/value-added value chain activities growing in importance due to changes in the underlying competitive environment, both societies see the opportunity for continued growth for their organizations as well the emergence of related associations that focus on other aspects of the competitive intelligence environment. Cam Mackey mentioned the Insights Association as one such example. Both also noted that the diversity of their membership results in titles that are not just called "competitive intelligence" but also market insight, market research, strategy, analytics, and more suggesting that the skill set that underlies the competitive intelligence professional is now being seen as a requirement in many related areas.

The rest of the papers in this special issue focus on giving readers insight into CI practice, research, and education.

The first article, "Intelligent Technology Scanning Aims, Content, and Practice" written by Dr. Brad Ashton, provides readers with an overview on technology intelligence (TI) and how it is developed, a primer on TI. The article leads the reader through the phases of the technical intelligence cycle: needs assessment, TI collection and processing, analysis and synthesis, production, and reporting, delivery and feedback. Dr. Ashton identifies the kinds of decisions that are made based on technical intelligence, the sources of information that are typically sought out and the analysis techniques that are used. The overlap between foresight and intelligence is particularly evident in this article in the analysis and synthesis section. Techniques described include foresight studies, scenarios analysis, scientometrics, disruptive technology assessments, patent analysis, literature mapping and bibliometrics. The article concludes with a comprehensive case study that leads the reader through the phases of the TI cycle. 
The next article by Nisha Sewdass and Jonathan Calof provides an overview into competitive intelligence. Sewdass and Calof report on a study conducted on SCIP (Strategic and Competitive Intelligence) members that examine how competitive intelligence practitioners define and operationalize/practice competitive intelligence. The comprehensive survey confirmed CI as a multidimensional concept involving planning collection, analysis, communication, and management activities. Only $29 \%$ of intelligence project time is involved collection activities. This article describes organizational requirements for competitive intelligence.

The following two works explore the role of competitive intelligence in innovation. In his article "Mapping Technology Landscape to Accelerate Innovation", Dr. Paap describes how competitive technical intelligence (CTI) can be used to help organizations "enhance their innovation efforts." The author describes science and technology intelligence (STI) and how it differs from competitive technical intelligence (CTI). The article contains many examples of CTI practice and lays out a framework for the effective development of CTI including detailed descriptions of key CTI tools. Dr. Paap concludes: "The reason why Competitive Technical Intelligence (CTI) is so critical is based on the understanding that innovation starts with information, not ideas. Thus, organizations that desire to be more innovative need to spend significant time on efforts to gather and assess information as a prelude to idea screening and selection and continue to look for changes that might affect project success throughout the execution phase. CTI provides a structured approach to anticipate the future and acquire the information required to generate innovative ideas and effectively manage their development".

The Mancilla-de-la Cruz et al. article "Scanning Additive Technologies for Competitiveness in the Pharmaceutical Industry" shows how competitive technical in telligence can be used for making R\&D decisions. This article reports on the use of multiple analytical techniques including hype cycle, multiple linear regression analysis using scientific documents and patents from SCOPUS and PatSnap to identify additive manufacturing (AM) based investments for reconfiguring drug delivery systems. The paper uses multiple CTI techniques which collectively identifies the "evolution of new drug delivery products where additive manufacturing is present." The techniques used by the authors identify the AM technologies that have the highest impact and for which $\mathrm{R} \& \mathrm{D}$ investment may be warranted. Where the Ashton and the Paap articles provide useful overviews with many examples, this article provides a single in depth application example using advanced analytical CTI techniques thereby showing the reader how CTI can lead to better decisions.

Marie-Luce Kuhn et al's article "Business Anticipatory Ecosystem Outside the "First World": Competitive Intelligence in South Africa" provides readers with a look at what defines a competitive intelligence ecosystem, its components, and how these components are measured. While most CI articles focus only on practitioners and how $\mathrm{CI}$ is practiced, the ecosystem concept notes that $\mathrm{CI}$ practice depends upon having an appropriate ecosystem to support organizations. Examples of the components of this ecosystem include:
- Service providers (consultants for example) that assist organizations in their CI activities;

- Universities that provide trained students (employees), conduct training programs for the existing employees and research that informs practice;

- Associations that provide among other things training and professional standards.

- Companies (private sector, government, NGOs) who practice CI as part of their ongoing business activities.

The article describes the components of the $\mathrm{CI}$ business ecosystem, measures to identify development within each component of the CI business ecosystem and then uses these measures to describe the CI business ecosystem in South Africa. The authors identify several weaknesses in the ecosystem especially at the association and consultant level and strengths in terms of firm level practice which was found to be more advanced than other firms in Africa and significant growth in academic involvement in competitive intelligence.

The article "Changing Priorities for Strategic Planning from National to Territorial Levels" by Henri Dou et al. shows readers the importance of applying competitive intelligence not just at the organizational level (to help companies) but at a regional and national level. The article focuses on how, by using competitive and strategic intelligence, it is possible to anticipate global changes and better manage a region during major global changes such as the current COVID-19 coronavirus crisis. The authors write: "It is in this context that a new Competitive and Strategic Intelligence must be developed to analyze the constraints, stresses, and unexpected threats that will impact communities. It must contribute to building local resilience allowing an acceptable response to the "predicament" and helping to create a new and ethical governance."

Foresight practitioners and researchers will appreciate the focus of the article on the territorial level, the tools of Competitive and Strategic Intelligence require the integration of what is termed "local actors". In particular, synergies between the actors, the complementarity of skills, and consensus need to be sought out in order to collectively pursue the results identified by the competitive and strategic intelligence process.

The final article by Leonardo Garcia, "Strategic Intelligence Teaching to Leverage Professional Success" provides readers with information on how competitive intelligence is taught to undergraduate students. It describes the projects assigned to students and the knowledge, skills, and attitudes that form the core of the author's university competitive intelligence program. The student's perceptions of how each of these knowledge, skills and attitude areas can impact their future professional success is provided with most respondents indicating that despite their not intending to pursue a CI career, they see how the skills, knowledge, and attitudes can have a positive impact upon any career.

I end this introductory article with a profound thank you to all those who submitted articles to this special issue. Foresight and STI Governance readers we hope will appreciate the mix of articles written by academics and practitioners, providing readers with a broad perspective on both the theory and application of competitive intelligence. Most of the articles are from authors who 
have been the recipients of various awards in recognition of their contributions to competitive intelligence. The fellow designation is awarded to those who are recognized in the field as leaders in competitive intelligence practice or scholarship are at the top of their field. Perhaps the strength of the authors for the special issue is reflected in the following review "incident." The reviewer appropriately noted that the description of an intelligence application within a major multinational in the paper was not the same as had been described in both the popular press and the academic literature. The author responded with "I know it's not the same, but I was the practitioner that ran that application in the multinational." To put it bluntly, in assembling this spe- cial issue, readers in many cases are hearing from the proverbial "horse's mouth", those that have been at the center of CI practice and research. We hope that providing a wide breadth of articles on various aspects of competitive intelligence from some of the top practitioners and researchers in the field will help Foresight and STI Governance readers learn and gain insight into this foresight-related field.

The article was prepared within the framework of the Basic Research Program at the National Research University Higher School of Economics (HSE) and supported within the framework of a subsidy by the Russian Academic Excellence Project '5-100'.

\section{References}

Calof J., Smith J. (2009) The integrative domain of foresight and competitive intelligence and its impact on R\&D management. R\&D Management, vol. 40, no 1, pp. 31-39.

Calof J. (2016) Integrated intelligence an exciting direction for SCIP, CI and Trade show intelligence. Competitive Intelligence Magazine, vol. 19, no 1, pp. 13-20.

Calof J. (2017) Reflections on the Canadian Government in competitive intelligence - Programs and impacts. Foresight, vol. 19, no 1 , pp. 31-47.

Calof J., Richards G., Smith J. (2015) Foresight, Competitive Intelligence and Business Analytics - Tools for Making Industrial Programmes More Efficient. Foresight-Russia, vol. 9, no 1, pp. 68-81.

Du Toit A. (2013) Comparative Study of Competitive Intelligence Practices between Two Retail Banks in Brazil and South Africa. Journal of Intelligence Studies in Business, vol. 3, no 2, pp. 30-39.

Du Toit A. (2015) Competitive intelligence research: An investigation of trends in the literature. Journal of Intelligence Studies in Business, vol. 5, no 2, pp. 14-21.

Greenwood R., Suddaby R., Hinings C. (2002) Theorizing Change: The Role of Professional Associations in the Transformation of Institutionalized Fields. Academy of Management Journal, vol. 45, no 1, pp. 58-80.

Lawton T., Rajwani T., Minto A. (2017) Why Trade Associations Matter: Exploring Function, Meaning, and Influence. Journal of Management Inquiry, vol. 27, no 1, pp. 5-9.

Mackey C. (2020) Strategic and Competitive Intelligence Professionals. Interview conducted by Jonathan Calof May 152020 , Ottawa.

Miller J. (2020) Special Libraries Association - Competitive Intelligence Division. Interview conducted by Jonathan Calof May 14, 2020, Ottawa.

Nordqvist M., Picard R., Pesämaa O. (2010) Industry Associations as Change Agents: The Institutional Roles of Newspaper Associations. Journal of Media Business Studies, vol. 7, no 3, pp. 51-69.

Peters S., Font X., Bonilla-Priego M. (2019) Why organizations join voluntary sustainable tourism associations: Implications for membership and sustainability monitoring systems. International Journal of Tourism Research, vol. 22, no 3, pp. 325-335.

Rajwani T., Lawton T., Phillips N. (2015) The "Voice of Industry": Why Management Researchers Should Pay More Attention to Trade Associations. Strategic Organization, vol. 13, no 3, pp. 224-232.

Rodriguez-Salvador M., Salinas-Casanova L. (2012) Applying Competitive Intelligence: The Case of Thermoplastics Elastomers. Journal of Intelligence Studies in Business, vol. 2, no 3, pp. 41-47. 